\title{
Estudo Químico e Antimicrobiano dos Extratos de Sementes e Folhas do Cumaru, Dipteryx odorata (Fabaceae)
}

\section{Chemical and Antimicrobial Study of Cumaru, Dipteryx odorata (Fabaceae) Seed and Leaf Extracts}

\author{
Gezilda Martins da Silva*a; Maria Lucidalva Ribeiro de Sousa ${ }^{a}$; Waldireny Caldas Rocha ${ }^{a}$; Adriana Dantas Gonzaga de \\ Freitas $^{\mathrm{a}}$
}

${ }^{a}$ Universidade Federal do Amazonas. AM, Brasil.

*E-mail: gezildamartins@gmail.com

\begin{abstract}
Resumo
O cumaru (Dipteryx odorata (Aubl.) é uma leguminosa da família Fabaceae, suas sementes são muito utilizadas na extração do óleo, o qual é bastante utilizado pela medicina popular como antiespasmódico, tônico, anti-inflamatório, reumatismos e antimicrobiano. A cumarina está presente na semente e também em toda a extensão da planta. O objetivo deste trabalho foi obter o óleo da semente e o extrato de folhas, realizar ensaios biológicos com o extrato e elaboração de um produto biotecnológico. O estudo foi realizado no laboratório de Química Orgânica da Universidade Federal do Amazonas, no qual as sementes foram coletadas, maceradas, para extração do óleo, em seguida, se realizou análise por cromatografia de camada delgada (CCD) do óleo da semente. As folhas foram maceradas, e preparadas as exsicatas, utilizou-se o óleo na produção do produto e para os ensaios biológicos frente às bactérias: Staphylococcus aureus, Escherichia coli, Klebsiella pneumoniae. Os resultados obtidos da extração das sementes foram o óleo e os cristais brancos em forma de agulha. Após análises cromatográficas (CCD) do extrato das folhas foi possível observar a presença de cumarina. O ensaio biológico com os cristais frente às bactérias $S$. aureus, E. coli, K. Pneumoniae apresentou halo de inibição. Assim, o óleo e a cumarina presentes na semente podem atuar como antibacteriano natural para o tratamento de várias doenças infecciosas causadas pela bactéria $S$. aureus. Foi possível formular um creme hidratante incorporando o óleo obtido da semente.
\end{abstract}

Palavras-chave: Extração do Óleo. Cumarina. Produto Biotecnológico.

\begin{abstract}
Coumaru (Dipteryx odorata (Aubl.) is a legume of the Fabaceae family, its seeds are widely used in oil extraction, which is widely used by folk medicine as an antispasmodic, tonic, anti-inflammatory, rheumatism and antimicrobial. Coumarin is present in the seed and also in the entire length of the plant. The objective of this work was to obtain the seed oil or the leaf extract, to perform biological tests with the extract and to elaborate a biotechnological product. The study was carried out in the Organic Chemistry laboratory, where the seeds were collected, macerated, for oil extraction, then a CCD analysis of the seed oil was carried out, the leaves were macerated, and the exsiccates were prepared, the oil was used in the product production and for biological tests against bacteria: Staphylococcus aureus, Escherichia coli, Klebsiella pneumoniae. The results obtained from the seeds extraction were oil and white crystals. After a chromatographic analysis (CCD) of the leaf extract, it was possible to observe the presence of coumarin. The biological assay with the crystals against the bacteria $S$. aureus, E. coli, K. Pneumoniae showed an inhibition halo. Thus, the oil and coumarin present in the seed can act as a natural antibacterial for the treatment of various infectious diseases caused by the bacteria S. aureus. It was possible to formulate a moisturizing cream incorporating the oil obtained from the seed.
\end{abstract}

Keywords: Cumaru Oil Extraction. Coumarin. Biotechnological Product.

\section{Introdução}

No Brasil, encontram-se pesquisas sobre os produtos oriundos do extrativismo e seus benefícios e limitações sociais, ambientais e econômicas. Um desses produtos é a semente de cumaru Dipteryx odorata (Aubl.), da qual é extraída a cumarina, utilizada na indústria de perfumaria e cosméticos e como fitoterápicos (CARVALHO, 1993). A planta possui aspectos químicos que contém características farmacológicas de extrema importância para a terapia de algumas doenças, como dores abdominais, reumatismo, tosse, bronquite, asma entre outras. Esta espécie é uma leguminosa da família Fabaceae, conhecida como cumaru, cumaru-verdadeiro ou cumaru-roxo (ALEXANDRE et al., 2008).
Segundo Paulo et al. (2003), as folhas de cumaru são compostas, imparipinadas e alternadas; medindo de $15 \mathrm{~cm}$ a $20 \mathrm{~cm}$ de comprimento, incluindo o pecíolo; a raque se projeta sem folíolos na zona apical; os folíolos apresentam de três a quatro pares subpostos; as lâminas dos folíolos medem de 7 $\mathrm{cm}$ a $12 \mathrm{~cm}$ de comprimento por $4 \mathrm{~cm}$ a $6 \mathrm{~cm}$ de largura, têm forma ovada-lanceolada, com pontos translúcidos, margem inteira, ápice acuminado e base redonda.

A árvore do Cumaru é frondosa, com um caule que pode atingir até $30 \mathrm{~m}$ de altura e $60 \mathrm{~cm}$ de diâmetro, em mata primária, embora possa atingir menor tamanho, quando em formações secundárias ou cultivadas (SOUZA et al., 2011). Possui flores vermelhas ou violetas de cheiro forte e agradável que no período 
de floração recobrem toda a copa. Seus frutos têm forma de drupa, de cor verde-amarela e quando maduros e secos se fendem liberando a semente coberta por uma película roxoescura, oleosa e aromática (ARAÚJO et al., 2004). As sementes da espécie apresentam um princípio ativo cristalizável, em forma rômbica, conhecida como cumarina uma alfa-lactona do ácido cumárico, que se apresenta como um princípio odorífero, de cheiro agradável (assemelhando-se a baunilha) e persistente, com sabor amargo. Tem peso molecular de 146, ponto de fulgor 162 , ponto de fusão $69-73{ }^{\circ} \mathrm{C}$, ponto de ebulição $298{ }^{\circ} \mathrm{C}$ e densidade 0,935 (ARAÚJO et al., 2004), com potencial para utilização de herbicida (OLIVEROS-BASTIDAS et al., 2013). A pesquisa teve como objetivo analisar as substâncias presentes nas sementes e folhas do Cumaru, avaliando o seu potencial antimicrobiano e farmacológico para a produção de cosméticos.

\section{Material e Métodos}

\subsection{Local de estudo}

O estudo químico e antimicrobiano dos extratos de sementes e folhas do cumaru foi realizado na Universidade Federal do Amazonas (UFAM), no Instituto de Saúde e Biotecnologia-ISB, localizado no município de Coari/AM, Brasil.

\subsection{Coleta do material vegetal}

Os frutos e as folhas de D. odorata foram coletadas na fazenda da Ufam, as sementes separadas da casca, manualmente, e em seguida, essas foram reduzidas em cadinho de porcelana e distribuídas em 16 cartuchos feito de papel filtro. Em cada cartucho foram adicionados 91,3 g de material vegetal, que foi submetido à extração por Soxhlet com hexano $(500 \mathrm{ml})$ por 8 horas consecutivas. O extrato foi seco em capela resultando em um óleo e cristais cumárico.

As folhas de cumaru (D. odorata) foram coletadas e foi feita assepsia com água corrente e sabão neutro, e pesadas na Balança de Precisão Bel 0,01g, 2200g S2202H . Em seguida, as folhas foram para a estufa do laboratório de botânica por 25 dias a $40^{\circ} \mathrm{C}$, para serem secas e extrair as substâncias presentes nas folhas do cumaru, primeiramente, as folhas foram picadas com tesoura e submetidas à extração por maceração (em temperatura ambiente) em que se colocaram $100 \mathrm{~g}$ das folhas picadas em um Erlermayer de $2000 \mathrm{~mL}$ no qual se adicionaram $900 \mathrm{~mL}$ de hexano, e o extrato que foi seco na capela apresentou cor escura (FIGUEIREDO et al., 2018).

\subsection{Análises Químicas}

O procedimento utilizado para as análises dos extratos do óleo do cumaru, cristal cumárico e da folha, foi a cromatografia de camada delgada (CCD), com placas cromatográficas de fase reversa de gel de sílica, com espessura de $10 \mathrm{~cm}$ de altura e $11 \mathrm{~cm}$ de largura, em que foram utilizadas 10 amostras e que cada amostra tinha peso de $3 \mathrm{mg}$ dos extratos utilizados, em seguida, foram solubilizadas em $1 \mathrm{~mL}$ de acetato de etila.
As placas foram inseridas em cubas cromatográficas com diferentes concentrações de solventes até que se encontrasse uma forma adequada para a visualização de cada banda. Em seguida, foi preparada a cuba em quatro proporções diferentes de água destilada e metanol, na qual cada extrato aplicado, em forma de banda, com auxílio de capilar de vidro sobre a placa cromatográfica reversa, depois destes processos, as placas cromatográficas foram eluídas, na cuba cromatográfica já preparada, com saturação de 15 a 40 minutos. E após a corrida do solvente sobre a placa, essa foi retirada da cuba cromatográfica e colocada para secar a temperatura ambiente. A visualização foi através do revelador físico em câmara escura com lâmpada UV (luz 365nm).

\subsection{Produto Biotecnológico}

Para elaboração do produto biotecnológico foram medidos $800 \mathrm{~mL}$ de água destilada, sendo que $300 \mathrm{~mL}$ da mesma foi colocada para aquecer com temperatura entre $40{ }^{\circ} \mathrm{C}$ a $60{ }^{\circ} \mathrm{C}$ e outra com $500 \mathrm{~mL}$ de água destilada se utilizou em temperatura ambiente. Em seguida, as duas proporções de água destilada foram unidas em Becker de $1000 \mathrm{~mL}$, adicionou-se a base hidratante, sendo utilizado o mix para homogeneizar a base até sua diluição, após adicionou-se polietilenoglicol, o nitrato de isopropila $\left(\mathrm{C}_{5} \mathrm{H}_{11} \mathrm{NO}_{2}\right)$, extrato glicólico de leite de cabra, essência do cumaru, corante (marrom e verde) e o óleo de cumaru. As fórmulas utilizadas se encontram no Quadro 1.

Quadro 1 - Reagentes utilizados para preparação do Hidratante

\begin{tabular}{|l|c|c|c|c|}
\hline \multirow{2}{*}{$\begin{array}{c}\text { Reagente } \\
\text { Utilizado }\end{array}$} & \multicolumn{4}{|c|}{ Quantidade de Regente Utilizado } \\
\cline { 2 - 5 } & $\begin{array}{c}\text { Fórmula } \\
\text { Base Hidratante }\end{array}$ & $\begin{array}{c}\text { Fórmula } \\
\mathbf{2}\end{array}$ & $\begin{array}{c}\text { Fórmula } \\
\mathbf{3}\end{array}$ & $\begin{array}{c}\text { Fórmula } \\
\mathbf{4}\end{array}$ \\
\hline Polietilenoglicol & $30 \mathrm{~mL}$ & $30 \mathrm{~g}$ & $100 \mathrm{~g}$ & $100 \mathrm{~g}$ \\
\hline $\begin{array}{l}\text { Ministrato de } \\
\text { isopropila }\end{array}$ & $50 \mathrm{~mL}$ & $50 \mathrm{~mL}$ & $50 \mathrm{~mL}$ & $30 \mathrm{~mL}$ \\
\hline Água destilada & $800 \mathrm{~mL}$ & $800 \mathrm{~mL}$ & $800 \mathrm{~mL}$ & $800 \mathrm{~mL}$ \\
\hline $\begin{array}{l}\text { Essência do } \\
\text { cumaru }\end{array}$ & $10 \mathrm{~mL}$ & $10 \mathrm{~mL}$ & $10 \mathrm{~mL}$ & $10 \mathrm{~mL}$ \\
\hline $\begin{array}{l}\text { Corante (marrom } \\
\text { e verde) }\end{array}$ & $0,2 \mathrm{~mL}$ & $0,2 \mathrm{~mL}$ & $0,2 \mathrm{~mL}$ & $0,2 \mathrm{~mL}$ \\
\hline $\begin{array}{l}\text { Óleo do cumaru } \\
\text { (Hexano) }\end{array}$ & $0,5 \mathrm{~mL}$ & $1,0 \mathrm{~mL}$ & $1,5 \mathrm{~mL}$ & $2,0 \mathrm{~mL}$ \\
\hline
\end{tabular}

Fonte: Dados da pesquisa.

\subsection{Análise antimicrobiana}

Os ensaios biológicos as atividades microbianas foram realizadas em Manaus (AM) no Laboratório de Pesquisa em Microbiologia no Departamento de Morfologia da Universidade Federal do Amazonas, no qual foi empregado o método de difusão em disco, as cepas utilizadas foram primeiramente reativadas em ágar Mueller-Hinton e após 24 horas de crescimento uma temperatura de $37^{\circ} \mathrm{C}$, as colônias isoladas foram inoculadas nas placas de Petri por $24 \mathrm{~h} \mathrm{a}$ temperatura de $37^{\circ} \mathrm{C}$. Após este período, as culturas bacterianas Staphylococcus aureus (ATCC 25923); Escherichia coli (ATCC 11229) e Klebsiella pneumoniae (ATCC 13899) 
foram transferidas para solução salina $(\mathrm{NaCl} 0,9 \% ; \mathrm{p} / \mathrm{v})$ até obter-se uma turvação equivalente ao padrão de 0,5 da escala de MacFarland, correspondente aproximadamente a $1,5 \times 10^{8} \mathrm{UFC} / \mathrm{mL}$. Uma alíquota de $100 \mu \mathrm{L}$ da suspensão de cada micro-organismo teste foi semeado em placas de Petri, contendo meios de cultura, segundo a técnica descrita por Shadomy e Spnllngrof (1980).

Discos de papel filtro foram posicionados nas placas, sendo essas semeadas com os micro-organismos testes se mantendo uma distância de $30 \mathrm{~mm}$ entre os discos para evitar interferências entre os possíveis halos de inibição, os discos foram empregados com $10 \mu \mathrm{L}$ de extrato sólido cristalino do óleo, empregados com dimetilsulfóxido (controle negativo) e para controle positivo foram utilizados $50 \mu \mathrm{g} / \mathrm{mL}$ de Tetraciclina, respetivamente.

Em seguida, as placas foram transferidas para geladeira $\left(4{ }^{\circ} \mathrm{C}\right)$, na qual foram mantidas durante 8 horas. Após esse período, as placas foram transferidas para estufa BOD a $37^{\circ} \mathrm{C}$, por 24 horas, para visualização de halos de inibição formados em resposta à difusão do possível composto bioativo contido no extrato da cumarina para o meio de cultura e ao desenvolvimento dos micro-organismos teste.

A leitura dos resultados constitui na aferição do diâmetro dos halos de inibição (em mm) formados ao redor do disco de papel. Os bioensaios foram realizados em triplicata, em que o resultado final resulta das médias dos halos, seguindo a metodologia utilizada por Costa et al. (2019).

\section{Resultados e Discussão}

\subsection{Produção dos óleos essenciais}

Por meio da extração das sementes do cumaru com o aparelho Soxhlet extraiu-se um óleo, que apresentou uma textura liquida com coloração amarelo claro e cristais de cor branca, que foram separados em frascos o óleo de cristais cumárico.

O óleo do cumaru possui ácidos graxos de cadeia longa como o ácido linoleico, ácido palmítico, ácido ortocumárico, ácido esteárico entre outros componentes químicos, sendo o aroma peculiar do óleo atribuído a um princípio ativo cristalizável, em forma rômbica, presente na semente (teor aproximado de 4\%), conhecido como cumarinas (ARAÚJO et al., 2004; SILVA et al., 2014).

O cumaru é usado no tratamento de distúrbios das funções vasculares e linfáticas, exercendo também ação antiinflamatória e antiedematosa e o óleo é utilizado no tratamento de diversas doenças e na formulação de novas fragrâncias (DEF, 1997; KOROLKOVAS, 1997).

\subsection{Folhas}

Após as folhas secas serem pesadas e trituradas foram alcançados os seguintes resultados, que podem ser observados, na tabela abaixo, na qual se demostra peso das folhas frescas, secas e trituradas, conforme observado no Quadro 2.
Quadro 2 - Peso das folhas do Cumaru - Dipteryx odorata

\begin{tabular}{|c|c|c|c|}
\hline $\begin{array}{c}\text { Material } \\
\text { Vegetal }\end{array}$ & $\begin{array}{c}\text { Peso Antes } \\
\text { da Secagem } \\
\text { (g) }\end{array}$ & $\begin{array}{c}\text { Peso Depois } \\
\text { da Secagem } \\
\text { (g) }\end{array}$ & $\begin{array}{c}\text { Peso } \\
\text { Triturado } \\
\text { (g) }\end{array}$ \\
\hline Folhas & $728,04 \mathrm{~g}$ & $380.99 \mathrm{~g}$ & - \\
\hline $\begin{array}{c}\text { Em 100g de } \\
\text { folha }\end{array}$ & - & $100 \mathrm{~g}$ & $100 \mathrm{~g}$ \\
\hline
\end{tabular}

Fonte: Dados da Pesquisa.

Foi utilizado o solvente hexano como padrão. Após a aplicação do solvente, a solução ficou com coloração verdeescuro, tornando visível uma substância que apresentou um baixo teor de cristais cumárico.

As folhas são muito utilizadas pela população no tratamento de várias doenças, ainda não tem relato na literatura sobre a propriedade dos cristais cumáricos e de seus óleos encontrados nas folhas cumaru e sobre seu potencial farmacológico (ALEXANDRE et al., 2008).

A espécie desperta grande interesse em função dos empregos a essa atribuídos na medicina popular (DEBORA et al., 2001). As plantas medicinais devem ser utilizadas, garantindo os efeitos benéficos e evitando que o uso incorreto possa causar efeitos indesejáveis e toxicidade (ANVISA, 2010).

Após a obtenção dos extratos se calculou o rendimento do material vegetal extraído da semente e da folha, que pode ser observado no Quadro 3.

Quadro 3 - Rendimento das folhas de Cumaru - Dipteryx odorata

\begin{tabular}{|l|c|c|}
\hline SOSolvente & Massa (g) & Rendimento (\%) \\
\hline Hexano & 2,68 & 2,7 \\
\hline
\end{tabular}

Fonte: Dados da Pesquisa.

\subsection{Análise Cromatográfica}

Para a cromatografia, as placas foram eluidas e o sistema mais adequado foi água destilada com metanol com a proporção de 6:4, conforme observado na Figura 1.

Figura 1 - O perfil cromatográfico do óleo da Dipteryx odorata. Fase móvel: (A) - Água destilada/metanol (1:1); (B) - Metanol (1:1); (C) - Água destilada/metanol (7:3); Água destilada/ metanol (6:4). Placas reveladas na luz UV $365 \mathrm{mn}$

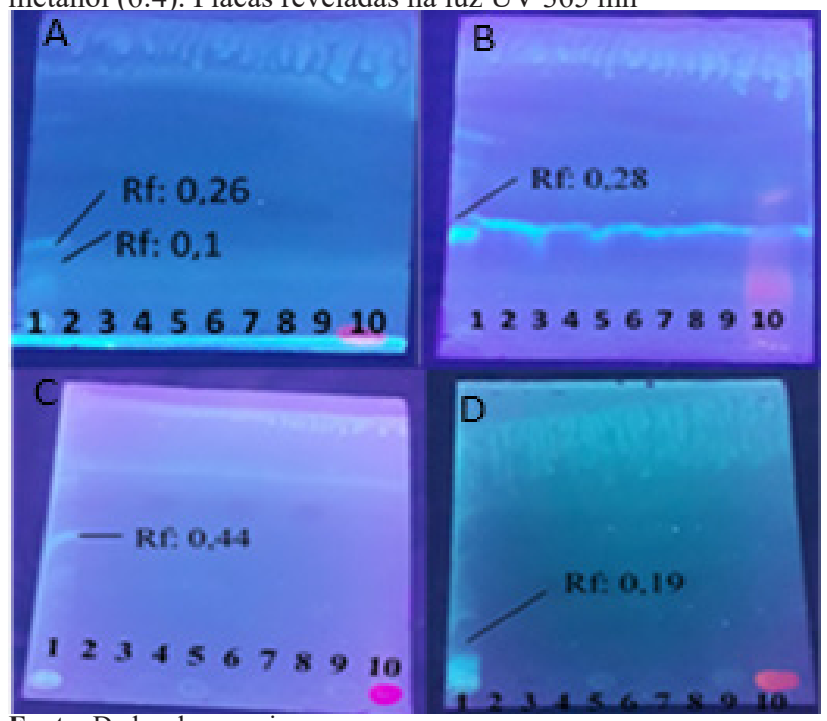

Fonte: Dados da pesquisa. 
Pode ser observado nas placas o resultado das separações cromatográficas do isolamento da cumarina. Na placa A, duas pequenas machas e na placa $\mathrm{B}$ se revelou uma única macha. Na placa $\mathrm{C}$ é observada uma macha e na placa $\mathrm{D}$ mostrou uma macha mais elevada em relação as outras placas. A cumarina é um dos principais responsáveis pelas atividades farmacológicas. E também utilizada no controle de qualidade, na produção dos extratos, em função do aroma característico que concede às folhas e sementes. $\mathrm{O}$ ácido o-cumárico sofre, em seguida, glicosilação e isomerização cis/trans, o que é fundamental para o processo de lactonização e formação final da cumarina. A cumarina é liberada apenas após hidrólise enzimática e lactonização, processos que ocorrem na danificação dos tecidos vegetais durante extração e processamento (SANTOS, 2005).

Quadro 4 - Respectivo valor do fator de redenção $\left(R_{f}\right)$

\begin{tabular}{|c|c|c|c|c|}
\hline $\mathbf{R}_{\mathrm{f}}$ & $\begin{array}{c}\text { Água/ } \\
\text { metanol } \\
(6: 4)\end{array}$ & $\begin{array}{c}\text { Água / } \\
\text { Metanol } \\
\mathbf{( 7 : 4 )}\end{array}$ & Metanol & $\begin{array}{c}\text { Água / } \\
\text { Metanol } \\
\mathbf{( 1 : 1 )}\end{array}$ \\
\hline & 0,19 & 0,44 & 0,28 & 0,$11 ; 0,26$ \\
\hline
\end{tabular}

Fonte: Dados da pesquisa.

$\mathrm{O}$ valor do $\mathrm{R}_{\mathrm{f}}$ obtido nos extratos das sementes do cumaru (Tabela 4) mostrou que a substância se separou de acordo com o esperado nas placas cromatográficas. Com sistema solvente adequado, com polaridades diferentes, os fatores contribuíram para a eficiência da separação da amostra do cumaru em CCD. Foi preciso encontrar a fase móvel capaz de arrastar os componentes da amostra até o topo da placa. Durante o processo de elaboração do produto dos quatro produtos produzidos com 0,$5 ; 1,1,5$ e 2,0 $\mathrm{mL}$ do óleo de cumaru com hexano, o que deu um melhor resultado, tanto na consistência quanto perfume e sem irritabilidade da pele, foi o produto que continha $0,5 \mathrm{~mL}$ de óleo de cumaru (Figura 2). Em função da quantidade em volume adicionado em cada um, sendo que o de óleo de cumaru não deve ser utilizado em grandes proporções por conter, em sua composição, a cumarina que é uma toxina tanto dérmica quanto oral podendo causar queimaduras sobre a membrana mucosa da pele e é extremamente irritante.

Figura 2 - Produto creme hidratante om óleo do cumaru
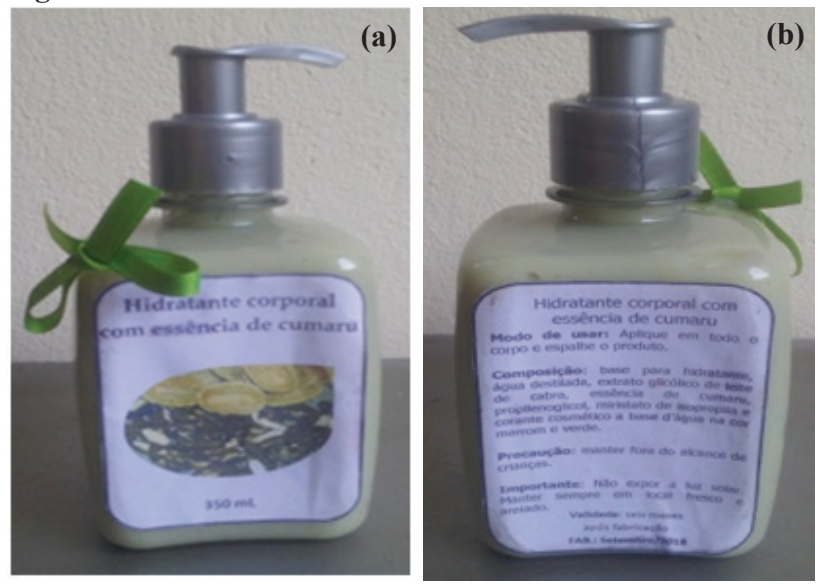

Fonte: Os autores.
Segundo Schmal et al. (2006), a cumarina é utilizada para retirar manchas escuras da pele e das mãos ao ser misturado em óleos neutros e também é utilizada como perfume em dose bem pequena, na indústria de produtos de beleza para fazer creme, perfume e xampu (PESCE, 2009). E para que os produtos sejam de boa qualidade é preciso ter manuseio correto dos materiais de laboratório para não sofrerem exposição em demasia. O produto elaborado tem um perfume agradável com vários benefícios para pele. Elaboração de um produto natural da Amazônia com potencial biotecnológico e inovador, com benefícios para quem o consumir. Ainda é necessário estudos de pesquisas que possam ampliar ainda mais as informações científicas do cumaru.

\subsection{Análise Antimicrobiana}

Os resultados obtidos em 24 horas (Quadro 5) demostraram que a ação antibacteriana da cumarina purificada de cumaru apresentou atividade antimicrobiana, apresentando halos de inibição de crescimento contra a bactéria Gram-positiva $S$. aureus e Gram-negativa E. coli. O melhor efeito bactericida foi sobre a o $S$. aureus, média de halos de 8 a $10 \mathrm{~mm}$ que pode ser visto na tabela abaixo. Enquanto na bactéria $K$. pneumoniae não houve formação de halo, ou seja, não ocorreu inibição do crescimento bacteriano. Segundo Madigan e Martinko (2004), as bactérias Gram - positivas são mais sensíveis antibióticos que Gram - negativa.

Quadro 5 - Diâmetros dos halos obtidos a partir dos extratos de Dipteryx odorata - cumarina purificada

\begin{tabular}{|l|c|c|c|}
\hline $\begin{array}{c}\text { Micro- } \\
\text { organismo }\end{array}$ & $\begin{array}{c}\text { Staphylococcus } \\
\text { aureus (ATCC } \\
\text { 25923) }\end{array}$ & $\begin{array}{c}\text { Escherichia } \\
\text { coli(ATCC } \\
\text { 11229) }\end{array}$ & $\begin{array}{c}\text { Klebsiella } \\
\text { pneumoniae } \\
\text { (ATCC 13899) }\end{array}$ \\
\hline Placa 01 & $8,85 \mathrm{~mm}$ & $17,32 \mathrm{~mm}$ & - \\
\hline Placa 02 & $10,06 \mathrm{~mm}$ & - & - \\
\hline Placa 03 & $10,22 \mathrm{~mm}$ & - & - \\
\hline
\end{tabular}

*Valores correspondem à média e ao desvio padrão do diâmetro dos halos de inibição em mm (-) ausência de zona de inibição.

Fonte: dados da Pesquisa.

Os resultados obtidos demonstram as propriedades bacterianas que o óleo de cumaru possui. Sendo que os diferentes mecanismos de resistência podem tornar cepa microbiana capaz de resistir parcial ou totalmente a ação, às vezes, não apenas de um antibiótico, mas de vários, pertencentes a uma mesma classe e às de classes diferentes (OTAIZA, 2002).

\section{Conclusão}

A pesquisa serviu para outros estudos futuros com o cumaru, e se espera que a partir deste trabalho seja possível verificar as substâncias presentes nas sementes e nas folhas do cumaru, como cumarina e o óleo, demostrando que produtos naturais apresentam potencial farmacológico, que pode ser utilizado na produção de cosméticos. E que análises feitas através de perfil cromatográfico (CCD) mostraram ser adequado para o desenvolvimento de estudos mais rápidos e 
simples, apresentando assim resultados satisfatórios e através da extração com soxhlet e maceração com maior rapidez na obtenção do extrato e do produto.

Os ensaios biológicos obtidos nos testes foram satisfatórios e as análises feitas com óleo cumárico na bactéria Grampositivas como $S$. aureus são mais sensíveis à ação inibitória determinada do que as Gram-negativas E. coli, podendo ser promissor para o desenvolvimento de novos fármacos.

\section{Referências}

ALEXANDRE, F.R.; BAGATINI, F.; SIMÕES, C.M.O. Interações entre fármacos e medicamentos fitoterápicos à base de ginkgo ou ginseng. Rev. Bras. Farm., v.18, n.1, p.117-26, 2008. doi: 10.1590/S0102-695X2008000100021

ARAUJO, V.; ECHEVERRIA, R.M.; PASTORE, F. Sistemas de extração de sementes de Cumaru. Produção não-madeireira e desenvolvimento Sustentável na "Amazônia". Brasília: UnB, 2004.

BESSA, D.T.O.; MENDONÇA, M.S.; ARAUJO, M.G.P. Morfoanatomia de sementes de Dipteryx odorata (AUBL) WILL (Fabaceae) Como contribuição ao estudo farmacognóstico de plantas da região da amazônica. Acta Amazônica, v.3, p.357- 364, 2001. doi: 10.1590/1809-43922001313364.

BRASIL. Ministério da Saúde. Agência Nacional de Vigilância Sanitária. Resolução de Diretoria Colegiada (RDC). Notificação de drogas vegetais. Diário Oficial da União, Brasília, DF, março, 2010.

CARVALHO, S.I.C. Caracterização dos efeitos alelopáticos de Brachiaria brizantha cv. Marandu no estabelecimento das plantas de Stylosanthes guianensis var. vulgaris cv. 85 Bandeirante. Viçosa: Universidade Federal de Viçosa, 1993.

COSTA, G.V.; ROCHA, W.C.; FREITAS, A.D.G. Microrganismos endofíticos encontrados no fruto da pupunheira (Bactris gasipaes Kunth) e seu potencial antimicrobiano. Rev Scie. Amaz., v.8, n.3, p.23-27, 2019.

FIGUEIREDO, R.C.; ROCHA, W.C.; FREITAS, A.D.G. Efeito
Inseticida do Óleo Essencial e Extratos Etanólicos das Folhas de Mastruz (Chenopodium ambrosioides L.) Sobre o Gorgulho do Milho (Sitophilus zeamais Mots). Ensaios Cienc., v.22, n.2, p.8084, 2018. doi: 10.17921/1415-6938.2018v22n2p80-84

KOROLKOVAS, A. Dicionário terapêutico Guanabara. São Paulo: Guanabara Koogan, 1997.

MADIGNAM, M. T. et al. Microbiologia de Brock. São Paulo: Presentice Hall, 2016.

OLIVEROS-BASTIDAS, A.D.J.; DEMUNER, A.J.; BARBOSA, L.C.A. Chemical Characterization by GC-MS and Phytotoxic Potential of non-polar and polar fractions of seeds of Dipteryx odorata (Aubl.) Wild. from Venezuelan regions. Quím. Nova, v.36, p.502-506, 2013. doi: 10.1590/S0100-40422013000400003

OTAIZA, O.R.F. Políticas de controle de antimicrobianos em nível hospitalar. Rev. Chil. Infectol, v.19, supl.3, p.219-221, 2002. doi: 10.4067/S0716-10182002019300010.

SCHMAL, B. et al. Manejo comunitário de produtos florestais não - madeireiros e fortalecimento local no município de Silves - AM. Manaus, 2006.

PESCE, C. Oleaginosas da Amazônia. Belém, PA: Museu, Paraense Emílio Goeldi, 2009.

SILVA, L. S. et al. Caracterização termoanalítica e quantificação do teor de Cumarina em sementes de Cumaru (Dipteryx odorata). In: CONGRESSO BRASILEIRO DE ANÁLISE TÉRMICA E CALORIMETRIA, 2014.

SANTOS, S.C. Caracterização cromatográfica de extratos medicinais de guaco: Mikania laevigata Schulyz Bip. ex Baker e $M$. glomerata Sprengel e ação de M. laevigata na inflamação alérgica pulmonar. Itajaí: Universidade do Vale de Itajaí, 2005.

SHADOMY, S.; SPINEL-INGROF, A. Susceptibility testing: With antifungal drugs. In: LENNETTE, E. (ED.). Manual of clinicial of microbiology. Washington: American Society for Microbiology, 1980.

SOUZA, E. L. et al. Qualidade do queijo de leite de cabra tipo Coalho condimentado com cumaru (Amburana cearensis A.C. Smith). Braz. J. Food Technol., v.14, n.3, p.220-225, 2011. doi: 10.4260/BJFT2011140300026. 